\title{
A Comparative Analysis of Different Commercial Lights
}

\author{
Shoaib Ahmed Shaikh ${ }^{1}$, Hamza Ali ${ }^{1}$, Mansaf Ali Abro' ${ }^{1}$, M Talha Iqrar ${ }^{1}$, Abdul \\ Manan Memon ${ }^{1}$
}

\begin{abstract}
:
There is a huge amount of financial losses due to usage of inefficient appliances in domestic, commercial and industrial sectors. A common appliance which occurs in the domestic, industrial and commercial loads is the lighting. This paper represents the study of different types of lights used in shopping malls by focusing on the different parameters of lights as Lumens, efficiency, power consumption, temperature. A survey was conducted in the shopping mall and measurements were also taken which shows the negative impact on the economic, power sector and environment. The proposed system was initiated by using the other types of lights with the help of DIALUX software which shows the improved results of cost, Lumens, temperature, power consumption and environmental benefits.
\end{abstract}

Keywords: Lighting overview; Lighting comparision; Shopping Mall survey; Environmental impacts; Power quality scenario.

\section{Introduction}

There are different types of loads used in the buildings as; inductive, capacitive and resistive. Lighting system consists of different lights which again comprises in the abovementioned load categories. This most common system keeps vital role and is crucial for ensuring its product, safety and luxury of the residents in the buildings. However, proper designing of the lighting is necessary for getting the desired requirement of output of illumination with least quantity of electricity use. From the report the Artificial Lighting consumption is up to $20-30 \%$ of the total commercial loads electricity consumption in a building [1]. As per guidance of IEA the lighting consumption from Global electricity consumption is distributed in percentage form as depicted in the pie chart in figure $1[2]$.

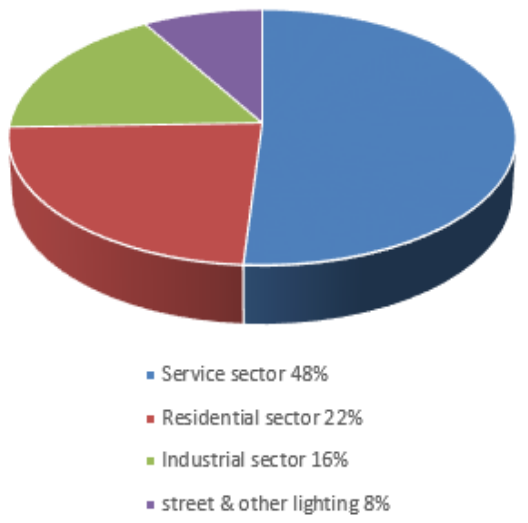

Fig. 1. Global electricity consumption of light [2].

${ }^{1}$ FEST, Hamdard University Karachi, Pakistan

Corresponding Email: skshaikh@outlook.com 
There is a huge gap in developing countries between demand and supply, surveys is being conducted and measures are being taken to reduce the consumptions of electricity as their demand side (DM) management part. It is estimated that by switching energy efficient technologies the reduction of energy up to $27 \%$ in residential side and $30 \%$ in commercial side could be received [3]. This has increased the usage of power electronic or non-linear energy saving devices. By extensive usage of these electronic equipment's, negative harmful impacts on the quality of power in the distribution system may arise. With extravagance one problem's solution will generate several other technical problems. Experiments and measurements have proved and clarified that preventation is more profitable and economical after the fact being known, rather than initiative of other problem's solution findings [4].

So many techniques occur to reduce the power consumption limit. Among these techniques replacement of inefficient energy lamps with the other efficient lamps is one of the best techniques.

Replacing the incandescent lights with standard energy efficient lights is economical in the summer season by the reduction of cooling needs in the building as well as reducing the lightning power consumption [5]. Surveys, Studies and measures have proved that there is a significant portion of lighting constitution in the country's total electricity consumption. In accordance with the Swedish Energy Agency report, around $23 \%$ of the country's total consumption of electricity occurs for lighting [6].

There is a momentous quantity of lighting consumption of the total energy resources in the world. In accordance with 2011 statistics, there are about $7.2 \%$ of lightning consumption of the developed and advanced world's primary energy assets which is accountable for the huge amount i.e. $430 \times 10^{\wedge} 9 \mathrm{~kg}$ of carbon emission [7]. With such a huge amount of $\mathrm{CO}_{2}$ emission and energy use, increasing the lightning efficiency by taking surveys and measurements is mandatory [8-9].

Electricity Rational consumption in buildings has become very essential and pertinent subject, particularly when growth of energy is becoming costlier and climate change may be initiated due to immoderate use through high release of greenhouse $\left(\mathrm{CO}_{2}\right)$ gases [10].

Energy consumption growth and emission of greenhouse $\left(\mathrm{CO}_{2}\right)$ gases in urban surroundings have made policies for energy saving and improving efficiency a prime concern in the energy plans of almost all countries [11]. Particularly in building, energy utilization for lightning is an extensive contributor to $\mathrm{CO}_{2}$ release, and its estimation has been taken which accounts for 20 to $40 \%$ of total energy utilization in buildings [12-13].

This paper represents the comparison of lights used in a shopping mall with its performance characteristics as power consumption, its temperature, Lumens, efficacy, etc., Environmental impacts due to lighting usage and some other power quality issues. We have designed a wooden box on a DIALUX software to check all the mentioned parameters with the help of instruments as watt meter, Lux meter and infra-red thermometer.

\section{Overview of Lights}

There are various types of lights used as indoor and outdoor applications. At a recent time, the opinion of utilizing the more eminent and enduring Light Emitting Diode (LED) in the applications which were consistently the province of inefficient and short life Compact Fluorescent Lamps (CFLs) and incandescent Lamps (ILs) has given the result of the development of LED lights. Relatively, 
in the general lightening system, LED technology is new and is developing continuously which have made it exigent for assessing its environmental aspects. LED lamps primarily are planned for domestic and commercial consumers. Moreover, LED lamps are environmentally affable as compared to other lamps like CFL has mercury inside it [14].

Each appliance has their own pros and cons. Despite this, it is necessary to use the standardized and efficient appliances as lights. In the selection of lights, the following important factors are considered shown in figure 2 .

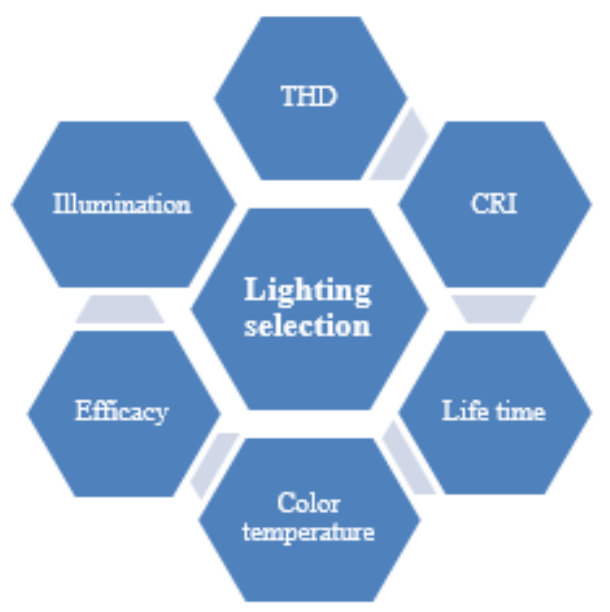

Fig. 2. Factors for the selection of lights.

Following are some types of lights which are familiar and mostly used for domestic and commercial purpose:

\subsection{Incandescent Lamp:}

This is a common household light bulb. It's simple yet brilliant. It was invented in late 1800s and amazingly it has hardly changed at all. In early it had on the top priority and in high usage due to lack of other lights inventions.

Heat is the main drawback of incandescent lamp and considered as highly inefficacious light bulb because loss of input energy is about $90 \%$ as heat output [15]. The efficacy range of IL is 1020lumen/watt, which depends on their construction features and temperature of the filament during operation [16]. Generally, the rated life period of IL is less $(<)$ around $1000 \mathrm{hrs}$ as compared to other lamps [17-18]. Halogen gas keeps vital role in incandescent lighting, special by adding this gas in incandescent lamp glass that has made the lifetime range higher.

According to the US market report 2010, higher consumption $(62 \%)$ of ILs has lowered the value of efficiency i.e. 19.1lumen/watt in the residential sector. This value could be improved by replacing the inefficient IL with other durable and energy efficient lights [19].

Researchers and experts tried to increase efficiency of IL and they asserted that the efficacy of HL may be increased to a value 45lumen/watt, but verification has not been achieved [20].

In European Union countries, due to above so many cons, EU commission had emphasized for the installation of IL to be banned from Sep 2012 on priority basis. It was not a proper solution to ban the product rather to give the alternate solution of making it an efficient. As this issue could be resolved by the usage of inert gases having emptiness $\mathrm{CO} 2$ emissions or other harmful gases which increased the cost due to high consumption. It is also estimated that electrical energy consumption in houses can be reduced up to $10-15 \%$ [21].

\subsection{Fluorescent Lamp:}

The common type of discharge lamp is a fluorescent lamp (FL) or tube used today in many sectors. This type of light is further classified as CFL and LFL. Inside a CFL or IFL, a UV light is produced due to passing of electrical charge through mercury gas. This light then results in the excitement of coated phosphorescent on the inner side of the tube for the production of the light. In fluorescent lighting, ballast is required for supplying an amount of current to start up. This can be attached on lighting fitting and 
can be integrated in the bulb's design. A fluorescent is a more efficient lamp as an incandescent lamp at present has been eliminated due to inefficiency and other drawbacks. Typically, the lamp's surpassing initial cost is neutralized by smaller energy cost [22]. Many shapes and sizes occur for Fluorescent Lamps. The Fluorescent Lamps (FLs) are recognized by their standard coding system which specifies the parameters and operating typical features with their relevant information. ' $\mathrm{T}$ ' is a key factor which denotes tabular and shows the diameter of tube, e.g. 1inch diameter itemizes T8 tube [23].

Due to less power consumption and more luminous, CFLs is accredited as Costeffective "Energy Saving Lamps" as compared to IL [24]. Equivalence of CFL and IL can be done with the ratio $4: 1$; this means that for the same light $80 \mathrm{~W}$ IL could be replaced by $20 \mathrm{~W}$ CFL [25].

\subsection{LED Lamp:}

A new type of device for lighting spreads over the planet the LED. It isn't a new device some way or another it has been used for years all around the world. What is new however, is being achieved greater power emission than a few years ago and making it provide white light. Their advantage that it consumes less energy $(<)$ as the traditional incandescent lamps (IL) uses high energy. A traditional lamp i.e. IL needs to be heated to emit light and a lot of energy is emitted and wasted in the heat form. Moreover, the materials suffer this heating problem at high temperature values. Recently, several types of energysaving lamps have become popular. The first energy saving lamps that replaced incandescent ones is fluorescents, which contain gases inside. On the other hand, LEDs can be made very small and solid elements are used in LEDs. In addition, LEDs are familiar due to their easily control, allow new applications such as generation of any light spectrum visibility of demand, optimizing energy costs and information transmission, this is known to be smart lighting.
A more efficacious, long lived LED lamp is also an environmentally friendly lamp than other light sources due to the empty mercury composition material. Today the high power white LED has increased luminous efficacy value reached up to 231lumen/watt in a laboratory [26].

From the Measures being taken and tests being conducted in the lab, it is shown that in domestic LED light and CFLs will not initiate any harmonic problem in the future of the network as compared to classic light bulbs [27-28].

\section{Methodology}

We have taken the measurands and counting of various lights used in shopping mall. The shopping mall consists of basement, ground floor and other four floors. There are so many shops in a shopping mall as shown in figure 3.

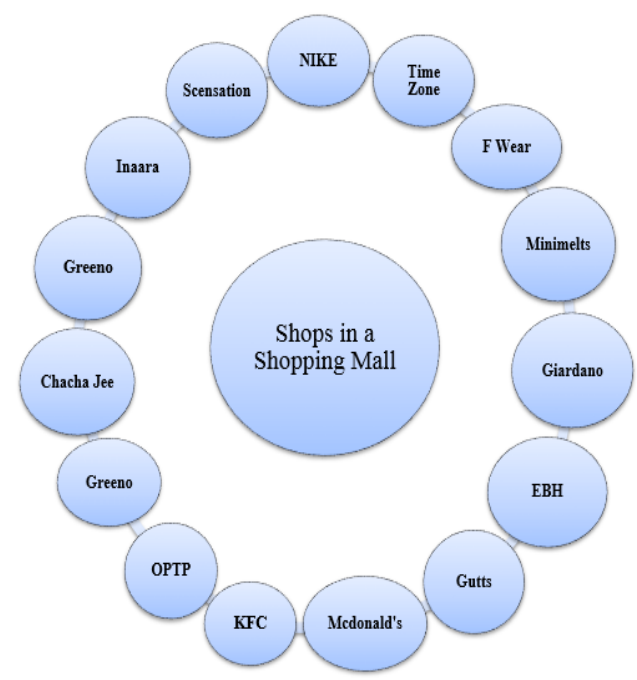

Fig. 3. Different shops in a shopping mall.

The most common lights used in a shopping mall are FL. CFL, IL, Halogen, HQI-TS, HPI-T, HPI-TS and HCI-T for different locations. As above mentioned that the lights performance can be observed by checking its parameters as; power rating, temperature, lumen etc. The existed data of lumen of different portions and shops of 
building is given in the form of bar charts in figure 4, figure 5 and figure 6 respectively.

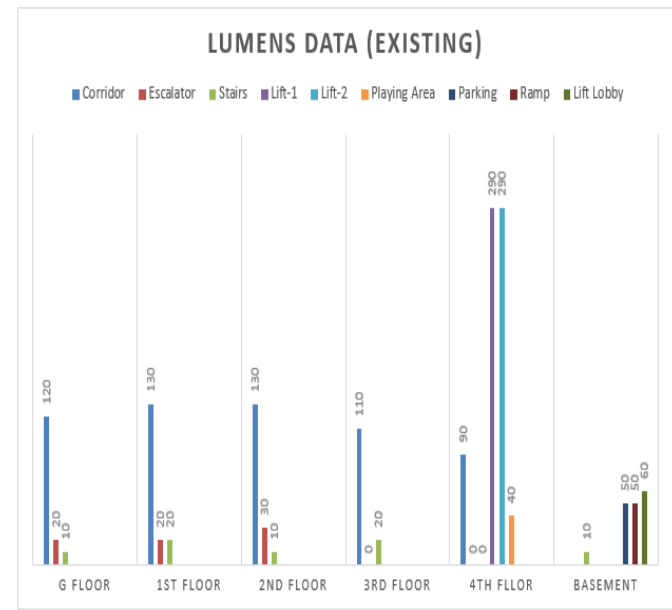

Fig. 4. Lumens data of the shopping mall.

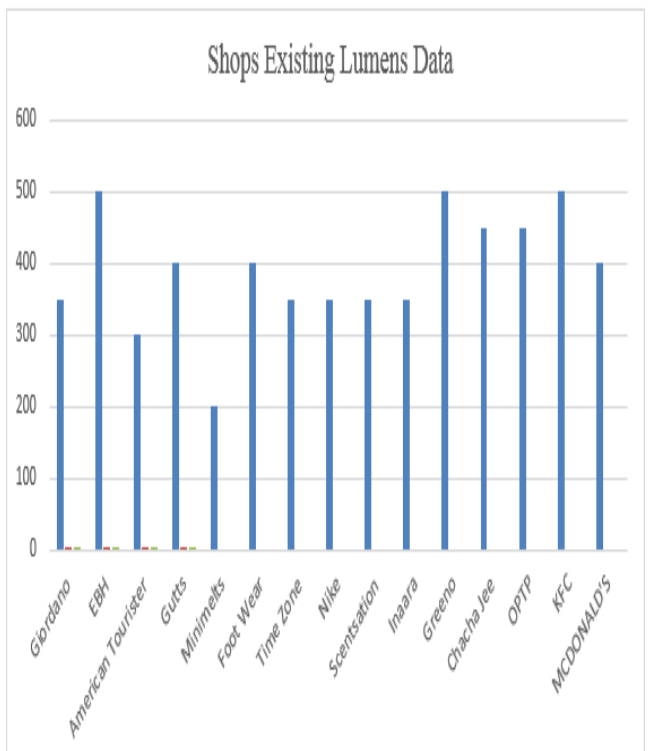

Fig. 5. Lumens data of shops in a mall.
Existing Power rating of lights

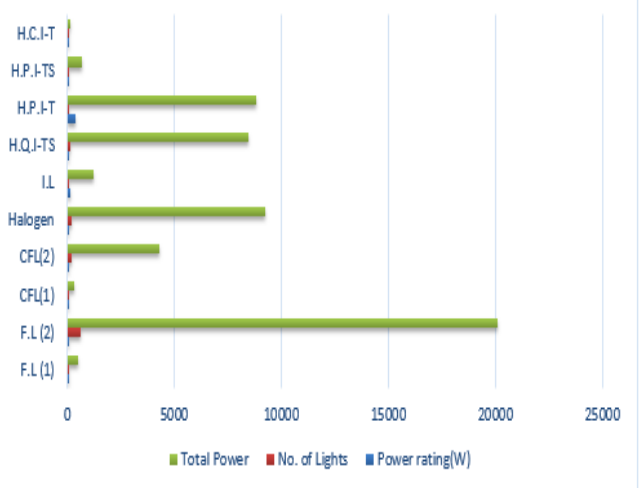

Fig. 6. Existed power rating of the lights (53767 or $53.767 \mathrm{kw})$.

We have checked the data of lighting used in a mall. Now we are going to select the other lights which are recommended as efficient and cost-effective lights. A wooden box is set which is designed by using the DIALUX software to check the results of exiting lights and recommended lights as shown in figure 7 . Our focus is to check the Lumens, temperature and power rating by using the instruments as Lux meter, infra-red thermometer and wattmeter.

For experiments, we take three existed lights and three recommended lights to check their performance in a designed box as shown in figure 8 .

The rating of existed lights is given as:

$\mathrm{A}_{1}=\mathrm{FL}=36 \mathrm{~W}$, 56lumens, $37^{\circ} \mathrm{C}$

$\mathrm{B}_{1}=\mathrm{CFL}=24 \mathrm{~W}$, 50lumens, $38^{\circ} \mathrm{C}$

$\mathrm{C}_{1}=$ Halogen $=50 \mathrm{~W}, 270$ lumens, $60.5^{\circ} \mathrm{C}$

The rating of recommended lights is given as:

$\mathrm{A}_{2}=\mathrm{FL}=16 \mathrm{~W}, 60.81 \mathrm{umens}, 32^{\circ} \mathrm{C}$

$\mathrm{B}_{2}=\mathrm{CFL}=11.7 \mathrm{~W}, 65.2$ lumens, $34.5^{\circ} \mathrm{C}$

$\mathrm{C}_{2}=$ Halogen $=7.8 \mathrm{~W}, 470$ lumens, $35.3^{\circ} \mathrm{C}$ 


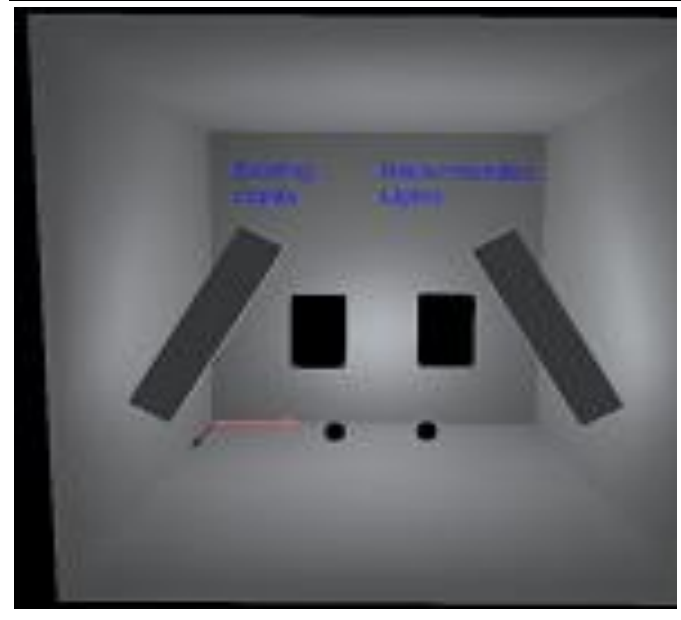

Fig. 7. Box selection on DIALUX software.

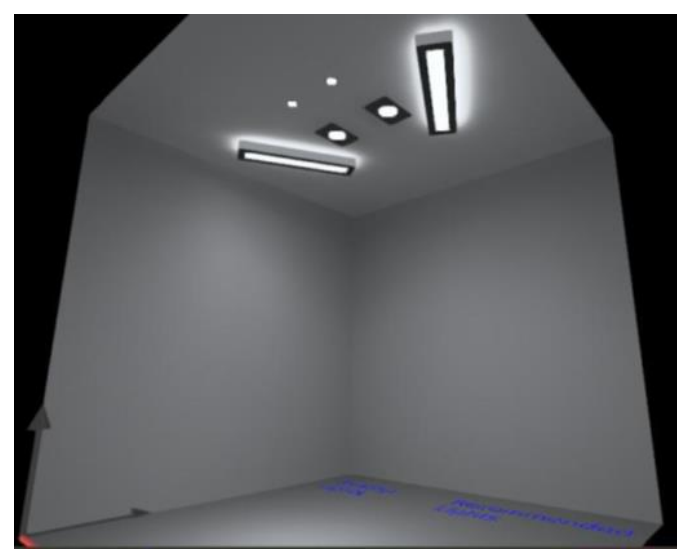

Fig. 8. Lights comparison.

After replacing the lights, we got the power rating result in the form bar chart as shown in figure 9, which clearly shows the improved results. It is an obvious that there is a direct relationship of power consumption with power rating and operating time. So, a positive result of the graph also depicts the recommended lights are cost-beneficial, high Lumens value and low temperature rating.
RECOMMENDED POWER RATING OF LIGHTS

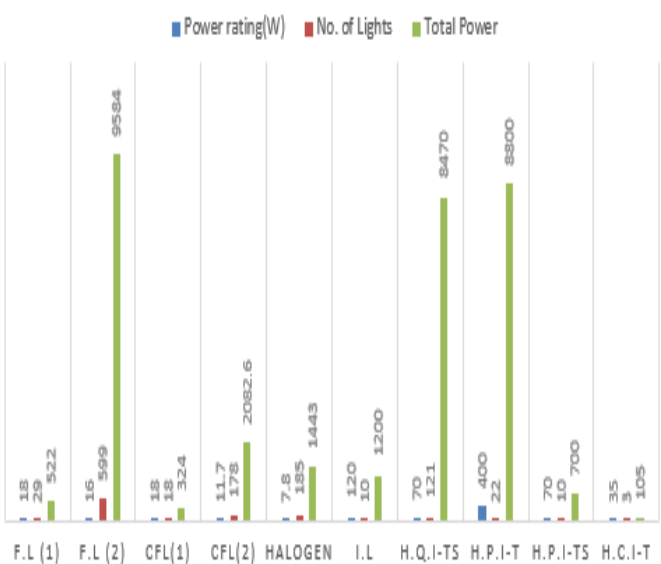

Fig. 9. Recommended power rating of lights.

The next comparison is of the Lumens and temperature mentioned in the charts given below in figure 10 and figure 11 respectively.

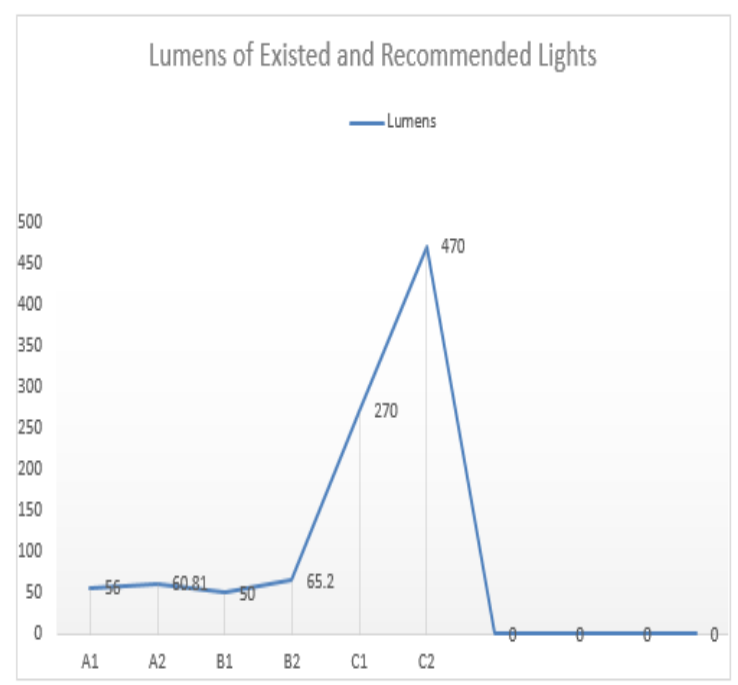

Fig. 10. Lumens of different lights. 
Temperature of Existed and Recommended Lights

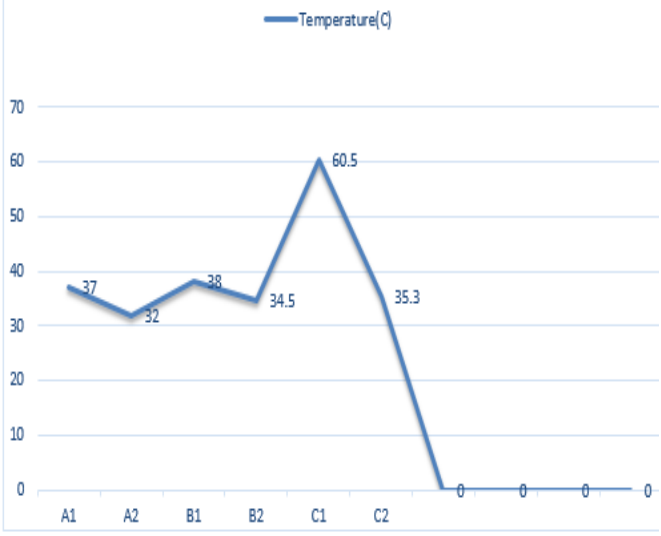

Fig. 11. Temperature of different lights.

\section{Energy and Enviromnetal impacts:}

A greenhouse gas is not a particular gas, but consists of other different gases. Greenhouse gases in an atmosphere trap heat and keep the planet warmer. Human beings, their activities and liveliness are the responsibility for all of the growth in greenhouse gas emission from the last 150years. The primary greenhouse emission sources in United States (US) are electricity, transportation, industry, commerci al/residential, agriculture and land use for forestry. In figure 12, total US greenhouse gas emission by Economic sector 2015 are presented in percentage form according to the US Environment protection agency [29].

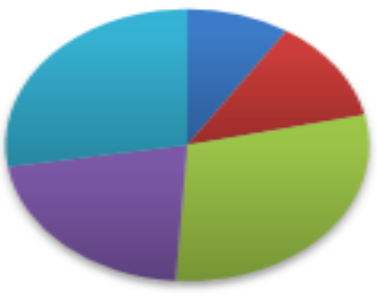

- Agriculture 19\%

- Commercial \& Residential $12 \%$

Electricity $29 \%$

- Ind ustry $21 \%$

- Transportation $27 \%$

Fig. 12. US greenhouse gas emission by economic sector 2015 .

Total emission in 2015 was equal to 6,587 Million Metric Tons of $\mathrm{CO}_{2}$ equivalent. The greenhouse $(\mathrm{GH})$ gases comprise of $\mathrm{CO}_{2}$, $\mathrm{N}_{2} \mathrm{O}, \mathrm{CH}_{4}$ \& Fluorinated gases. A Pie chart of the total emission is given in figure 13.

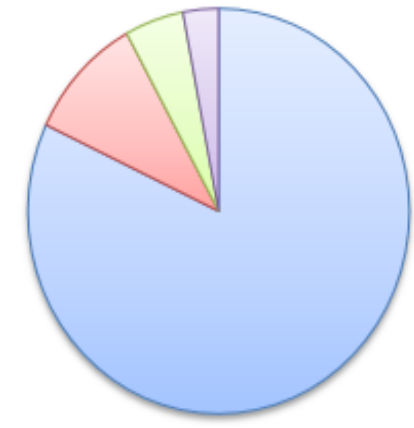

$\square$ Carbon Dioxide $82 \% \square$ Methane $10 \%$

$\square$ Nitrogen oxide 5\% $\quad$ Flu orinated gaes 3\%

Fig. 13. Greenhouse gases emission.

The energy we utilize in our homes, mainly dependent on the atmosphere where we live and the different type devices that consume energy which are in our usage. Figure 14 shows the pie chart of residential energy consumption in percentage for the year 2009 [30]. 


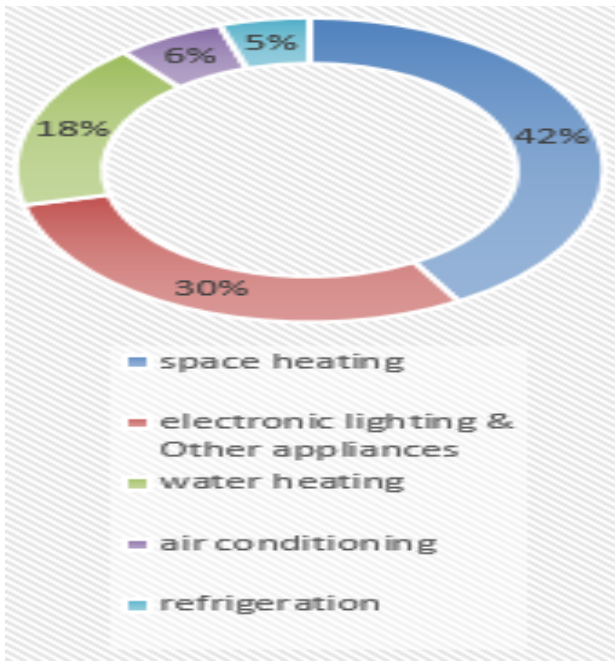

Fig. 14. Residential energy consumption survey (RECS) 2009.

It is not widely considered and focused that the biggest and main reason of greenhouse gas emission is lighting. The energy consumed to supply lighting necessitates greenhouse gas emission of 19x102 megatons of $\mathrm{CO}_{2}$ /year throughout the world [31]. As each of us are producing $\mathrm{CO}_{2}$ gas from our daily activities as by turning the lights and it is already discussed above that lightning is one of the main sources of producing $\mathrm{CO}_{2}$ gas. We can reduce the $\mathrm{CO}_{2}$ emission gases with the usage of advanced lighting technology. Light bulbs are not associated with carbon dioxide but when we switch on the lights in our homes, this deadly $\mathrm{CO}_{2}$ gas in initiated in the generation of electricity on which those light bulbs powers. Changing our incandescent light bulbs or other types to new, more efficient and high environmental friendly LED lamp is the best for an ease reduction of carbon emissions.

Vitae Energy Consulting claims in his recent report that saving could be $£ 1.4$ billion a year on its energy spend industry in the UK and 10 million tons (MTs) of $\mathrm{CO}_{2}$ emissions annually by updating and modernizing the lighting stock on the usage of today's energyefficient and advanced lighting technologies.
The study and survey was carried over 500 companies in the warehousing and manufacturing sector and concluded that, a quarter of the companies in around surveyed and observed, the lighting system accelerated in the 1950s and consumed almost inefficient light bulbs that were sheltered in fittings not ameliorated for efficient light radiation. The study also showed that energy usage of industrial lighting energy could be cut relatively $60 \%$ if the fittings were optimized for using the specially designed reflectors for increasing the overall light.

\section{Power Quality Scenario}

Incandescent light has unity power factor as it is a purely resistive load type lamp. The main advantage of this lamp is that it does not need any electronic driver to start thus no any harmonic issue occurs. Whereas other lamp types such as LED lamps and discharge lamps require special drivers for the operation purpose, hence produces harmonic distortions in the supply current wave which disturbs the sinusoidal waveform [32-33].

Inductance in ballast in case of discharge lamps has low lagging power factor which disturbs the power triangle, so it is necessary to compensate. A capacitor for compensation is the best solution to be connected in parallel with blast to increase the value the power factor (P.f) in a florescent lamp. In new T5 Fluorescent lamp (FL) luminaire, there is improved P.f of a good value 0.9 and improved THD value $(<15 \%)$ due to usage of electronic ballast [33]. Whereas CFL of low rating with electronic ballasts have low leading power factor (0.5-0.6). Due to weight and space issues, low rating CFLs cannot be compensated individually [34]. Thus, power factor can be improved centrally in a given location if low rated CFLs with large quantity are used [35]. LED lamps designed as a source of voltage with a low rating of series resistance to limit the line current $\mathrm{I}_{\mathrm{L}}$, have usually much higher power factor than other 
lamps (discharge lamps). According to the United states Dept. of the energy star program, the acceptable range of power factor (P.f) 0.70.9 has been mandated for domestic and commercial Light Emitting diode Lamps [36], also UK Energy Saving Trust has mandated a minimum acceptable power factor (P.f) of 0.7 with a prolonged objective having power factor of 0.9 for integral Light emitting diode lamps [34].

\section{Conclusion}

A common load which is always on peak usage in each season is of lighting. It is very important to select the proper lights for domestic, commercial and industrial usage. This paper focus on the profile of all types of lights specifically FL, CFL, IL and halogen. A survey of a shopping mall was being conducted for different types of light on different locations. There were lot of impacts due to existed lights as lumens, efficacy, temperature, power losses etc. Then other types of light with different parameters were recommended by selecting a wood box with a usage of DIALUX software which showed the improved results in this research work. This is not only important for the performance of lights but very much cost beneficial from economic point of view. On the other hand, it is also seen from consumption and environmental point of view that the IL lamp has the $\mathrm{CO}_{2}$ emissions issues and high energy consumption. Halogen lamp was better than IL due to inert gases existed inside it which are not so worse than IL lamp. FL and CFL lamp was much better than IL lamp and Halogen due to low consumption of energy and environmental friendly. Furthermore, the above lights can also be replaced with the new technology of lights as "LED" which have led all types of lights due to several advantages. Our next task is to work on the LED lights and on the cons of above lights to give the improved techniques.

\section{ACKNOWLEDGMENT}

This is the most difficult part of the paper to give rewarding words to others on their life or work. First and the foremost, we give thanks to Almighty Allah who gave us the inner strength, resource and ability to complete our comprehensive research successfully, without which all our efforts would have been in vain. Than we acknowledge the support and constant encouragement of Hamdard Institute of Engineering and Technology, Hamdard University, Karachi, throughout the completion of this research. Last but not the least we wish to express our sincere thanks to all our friends for their goodwill and constructive ideas.

\section{REFERENCES}

[1] JC. Lam, DHW. Li, and S. Cheung, "An Analysis Of Electricity End-Use In AirConditioned Office Buildings In Hong Kong," Building Environ, vol. 38, no. 3, pp. pp. 493-8, 2003.

[2] Energy Conservation In Buildings And Community Systems Program (Ecbcs) Annex 45 Guidebook On EnergyEfficient Electric Lightingfor Buildings, Edited By Liisa Halonen, Eino Tetri \& Pramod Bhusal, International Energy Agency, 2010.

[3] J. Trifunovic, J. Mikulovic, Z. Djurisic, M. Djuric, and M. Kostic, "Reductions in Electricity Consumption And Power Demand in Case of the Mass use of Compact Fluorescent Lamps," Energy vol. 34, pp. 1355-1363, 2009.

[4] N. R. Watson, T. L. Scott, S. Hirsch, "Implications For Distribution Networks of High Penetration Of Compact Fluorescent Lamps," IEEE Transactions On Power Delivery, vol. 24, pp. 15211528, 2009.

[5] R. Saidur, "Energy Consumption, Energy Savings, and Emission Analysis in 
Malaysian Office Buildings," Energy Policy vol. 37, pp. 4104-4113, 2009.

[6] M. Bladh and H. Krantz, "Towards A Bright Future? Household Use Of Electric Light: A Microlevel Study," Energy Policy, vol. 36, pp. 3521-3530, 2008.

[7] K. Powell, "Panel4: Lessons From The Field. Solid-State Lighting Program: U.S. Department Of Energy," 2011. Available From:/Http://Apps1.Eere.Energy.Gov/B uildings/Publications/Pdfs/Ssl/Powell_L essons_Sslmiw2011.Pdfs (Access On:3 August 2012).

[8] J. R.-M. Belizza, S. -P. Claudia, "Electricity Sector Reforms In Four Latin- American Countries and Their Impact On Carbon Dioxide Emissions and Renew- Able Energy," Energy Policy vol. 38, pp. 6755-6766, 2010.

[9] Sheinbaum, C., Rui'Z, B.J., Ozawa, L., 2011.Energy Consumption And Related Co2 Emissions In Five Latin American Countries: Changes From 1990 To 2006 And Perspectives. Energy, vol. 36, 36293638.

[10] Linhart F, Scartezzini J-L. Minimizing Lighting Power Density In Office Rooms Equipped With Anidolic Daylighting Systems. Solar Energy 2010; 84(4):58795.

[11] Pérez-Lombard L. A Review On Buildings Energy Consumption Information. Energy Build 2008; 40:3948.

[12] Energy Information Administration. Commercial Buildings Energy Consumption Survey; 2003

[13] Brunner, E.J., Ford, P.S., Mcnulty, M.A., Thayer, M.A., 2010. Compact Fluorescent Lighting And Residential Natural Gas Consumption: Testing For Interactive Effects. Energy Policy 38, 1288-1296.

[14] Beth Daley, "Mercury Leaks Found As New Bulbs Break: Energy Benefits Of
Fluorescents May Outweigh Risk," The Boston Globe, February 26, 2008

[15] Brunner, E.J., Ford, P.S., Mcnulty, M.A., Thayer, M.A., 2010. Compact Fluorescent Lighting And Residential Natural Gas Consumption: Testing For Interactive Effects. Energy Policy 38, 1288-1296.

[16] Doe, 2012a. 2010 U.S. Lighting Market Characterization. Solid-State Lighting Program:U.S. Department Of Energy. Available From: /Http://Apps1.Eere.Energy.Gov/Building s/Publications/Pdfs/Ss1/2010-Lmc-FinalJan-2012.Pdfs(Access On:1august2012).

[17] Osram, 2009. Life Cycle Assessment Of Illuminants A Comparison Of Light Bulbs, Compact Fluorescent Lamps And Led Lamps.

[18] Simpson, R.S., 2008. Lighting ControlTechnology And Applications. Focal Press.

[19] Doe, 2012a. 2010 U.S. Lighting Market Characterization. Solid-State Lighting Program:U.S. Department Of Energy.Available From: /Http://Apps1.Eere.Energy.Gov/Building s/Publications/Pdfs/Ssl/2010-Lmc-FinalJan2012.Pdfs(Accesson: 1 august2012).

[20] Eceee, 2011. Evaluating The Potential Of Halogen Technologies. European Council For An Energy Efficient Economy.Available From: /Http://Www.Eceee.Org/ Eco_Design/Products/Directional_Lighti ng/Halogen_Technologies_Report/ Eceee_Report_Halogen_Technologiess (Access On:27 July 2012).

[21] Europa, 2009. Phasing Out Conventional Incandescent Bulbs (Faq-Press Release). Available From: /Http://Europa.Eu/Rapid/Pressreleasesact ion.Do?Reference $=\quad$ Memo/09/368s (Access On:20 September2012).

[22] Onaygil S, Güler Ö. Determination Of The Energy Saving By Daylight 
Responsive Lighting Control Systems With An Example From Istanbul. Building And Environment 2003; 38(7):973-7.

[23] Roisin B, Bodart M, Deneyer A, D’herdt P. Lighting Energy Savings In Offices Using Different Control Systems And Their Real Consumption. Energy And Buildings 2008;40(4):514-23

[24] Simpson, R.S., 2008.Lighting ControlTechnology And Applications. Focal Press.

[25] Vito, 2007. Eco-Design Study Lot 19Domestic Lighting. Preparatory Studies For Eco-Design Requirements Of Eups. Available From: /Http://Www.Eup4light.

[26] Cree: Cree 231 Lumen Per Watt Led Shatters Led Efficacy Records. [Online]. Available: Http://Www. Cree.Com/Press/Press_Detail.Asp? $\mathrm{I}=1304945651119$. [Accessed November 17, 2011].

[27] S.K. Ronnberg, M.H.J. Bollen, Et. A! Harmonic Emission Before And After Changing To Led And Cfl - Part I: Laboratory Measurements For A Domestic Customer, 14th International Conference On Harmonics And Quality Of Power, P. 1-7,2010.

[28] S.K. Ronnberg, M. Wahlberg, Et. A! Harmonic Emission Before And After Changing To Led And Cfl - Part Ii: Field Measurements For A Hotel, 14th International Conference On Harmonics And Quality Of Power, P. 59-67, 2010.

[29] Https://Www.Epa.Gov/Ghgemissions/In ventory-Us-Greenhouse-Gas-EmissionsAnd-Sinks

[30] Https://Www.Eia.Gov

[31] Key World Energy Statistics 2007 (International Energy Agency, Paris, France, 2007).

[32] Philips, 2009. The Abc's Of Electronic Fluorescent Ballasts: A Guide To Fluorescent Ballasts. Available From: /Http://Www.Advance.Philips.Com/Doc
uments/Uploads/ Literature/Rt-8010-

R03_Abc.Pdfs (Accesson:3 August2012).

[33] Akashi, Y.,2002.T5 Fluorescent Systems. The Lighting Research Center, National Lighting Product Information Program(Nlpip). Available From: /Http://Www.Lrc.Rpi.Edu/Programs/Nlp ip/Publicationdetails.Asp?Id=284\&Type $=2$ s (Access On: 5august2012).

[34] CIE, 2012. Led Bulb Placement Meeting New Challenges. Components In Electronics. Available From: /Http://Content.Yudu.Com/A1wimc/Ciea pril12/Resources/52.Htms (Accesson:5 August2012).

[35] Sehat Sutardja, 2009. Green Opportunities. Marvell Semiconductor,Inc. Available From: /Http://Www.Marvell.Com/Environment /Assets/Marvell-Green-Opportu Nities.Pdfs (Access On:20july2012).

[36] ECN Magazine, 2011. Power Factor Correction Techniques Inled Lighting. Available From: /Http://Www.Ecnmag.Com/Products/201 1/08/Power-Factor-CorrectionTechniques-Led-Lightings (Access On:22 September2012). 